\title{
Arena do Morro e Museu do Amanhã: dois lugares em ação
}

\author{
Arena do Morro and Museu do Amanhã: two places in action
}

Paulo Afonso Rheingantz ${ }^{[a, b]}$, Rosa Maria Leite Ribeiro Pedro ${ }^{[c]}$, Fabiola Belinger Angotti ${ }^{[0]}$, Marcelo Hamilton Sbarra ${ }^{[0]}$

\begin{abstract}
[a] Universidade Federal do Rio de Janeiro (UFRJ), Programa de Pós-graduação em Arquitetura, Rio de Janeiro, RJ, Brasil
[b] Universidade Federal de Pelotas (UFPel), Programa de Pós-graduação em Arquitetura e Urbanismo, Pelotas, RS, Brasil

[c] Universidade Federal do Rio de Janeiro (UFRJ), Programa de Pós-graduação em Psicologia, Rio de Janeiro, RJ, Brasil
\end{abstract}

\section{Resumo}

Este artigo, alinhado com a perspectiva sociotécnica, discute o entendimento de lugares em ação como laboratórios ou interfaces que aprendem e performam conhecimentos e que, além de modelados por diferentes "políticas ontológicas", são, a um só tempo, situados ou localizados e globais. Se qualquer lugar também é global, é conveniente explorar como ele inclui Outros. Para tanto, recorremos às quatro espacialidades propostas por John Law e Annemarie Mol (a euclidiana, cuja prevalência tende a ser naturalizada, a de redes, a fluida e a do fogo). Para explicar como as espacialidades se produzem e se misturam nos lugares em ação e recrutam Outros aliados, exploramos os processos de fabricação da Arena do Morro em Natal, no Rio Grande do Norte, e do Museu do Amanhã, no Rio de Janeiro, dois projetos-lugares em ação que, além de locais, regionais e globais, são dispositivos “móveis imutáveis", “móveis mutáveis” e “imóveis mutáveis”, territórios contestados que não podem ser reduzidos àquilo que "são" ou "significam".

Palavras-chave: Arena do Morro. Museu do Amanhã. Espacialidades. Lugares em ação.

\section{Abstract}

This article is aligned with the socio-technical perspective and discusses the understanding of places in action as laboratories or interfaces that learn and perform knowledge that, even though shaped by different "ontological politics", are simultaneously situated or localized and global. If any place is global, it is worth exploring how it includes others. Therefore, we used the four spatialities proposed by John Law and Annemarie Mol - the euclidean, whose prevalence tends to be naturalized, the networks, the fluid and the fire. To explain how the

PAR é arquiteto, doutor, professor do Programa de Pós-graduação em Arquitetura da Universidade Federal do Rio de Janeiro (UFRJ) e professor visitante do Programa de Pós-graduação em Arquitetura e Urbanismo da Universidade Federal de Pelotas (UFPel), e-mail: parheingantz@gmail.com

RMLRP é psicóloga, doutora, professora do Programa de Pós-graduação em Psicologia da Universidade Federal do Rio de Janeiro (UFRJ), e-mail: rosapedro@globo.com

FBA é arquiteta, doutoranda do Programa de Pós-graduação em Arquitetura da Universidade Federal do Rio de Janeiro (UFRJ), e-mail: fabiolabelangotti@uol.com.br

MHS é arquiteto, doutorando do Programa de Pós-graduação em Arquitetura da Universidade Federal do Rio de Janeiro (UFRJ), e-mail: marcelosbarra@gmail.com 
spatialities are produced and mixed in places, action and recruit other allies, we explore the manufacturing processes of the Arena do Morro in Natal/RN and Museu do Amanhã in Rio de Janeiro/RJ, two projects-places in action that, in addition to local, regional and global, are also devices "immutable mobiles", "mutable mobiles" and "immobiles mutable", being disputed territories which cannot be reduced to what they "are" or "mean".

Keywords: Arena do Morro. Museu do Amanhã. Spacialities. Places in action.

\section{Introdução}

O presente artigo se propõe a explorar possibilidades de conexão entre a Teoria Ator-Rede (TAR) e a Arquitetura e Urbanismo (AU), tomando como materialidades privilegiadas a Arena no Morro, em Natal, no Rio Grande do Norte, e o Museu do Amanhã, no Rio de Janeiro. 0 encontro TAR-AU pode contribuir para pensar as associações entre pessoas e coisas, matéria e significado (Fallan, 2008), especialmente uma ontologia alternativa para esses "objetos" desordenados e evasivos que são os edifícios e os lugares (Farías, 2010a) e seus modos de "estar presente" (Farías \& Bender, 2010).

Não se busca "aplicar" conceitos da TAR à AU, mas, antes, explorar interfaceamentos que, como indica Michel Serres (1999), precisam ser feitos e refeitos a cada encontro. Nesse percurso de exploração, alguns princípios são orientadores. Primeiramente, que lugares e edifícios são performados ou trazidos à existência (Mol, 2008) nas redes de objetos, materialidades, tecnologias, natureza, organismos e seres humanos (Farías, 2010a). De modo análogo, a urbanidade é uma qualidade que não preexiste nos lugares, ruas, edifícios etc., mas que emerge de múltiplos processos

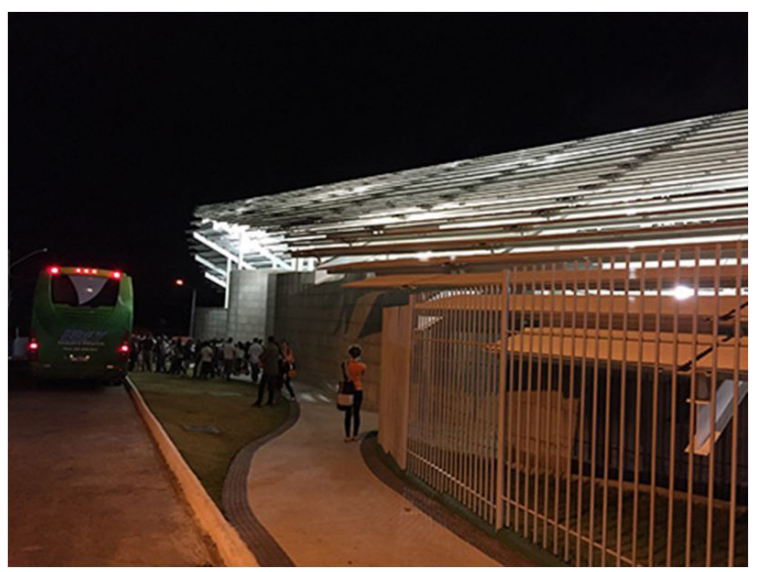

Figura 1 - Arena do Morro (vista externa noturna) Fonte: Acervo dos autores (2015). de associações (Farías, 2010a). Apresentam-se ainda os edifícios e os lugares a partir de uma duplicidade que os caracteriza, simultaneamente, como tecnologias e como tipos (Guggenheim, 2010). Ao mesmo tempo que são singulares - têm localização e forma estável -, eles podem acolher diferentes usos - transformados em outro tipo de construção com relativa facilidade, apesar de aparentemente intactos. Por operarem de modo simultâneo com diferentes usos e atores, eles podem ser considerados tecnologias instáveis, quasetecnologias (Guggenheim, 2010) ou imóveis mutáveis (Latour, 2000; Guggenheim, 2010). Como decorrência, afirma-se que os edifícios não são objetos estáticos (Latour \& Yaneva, 2008). Transformados por seus usuários, pelos novos dispositivos e sistemas tecnológicos, pelas ações que acontecem em seu interior e exterior, eles são objetos em movimento, mesmo depois de construídos. Por fim, são problematizadas a noção de fronteira e a clássica separação linear de território, "[...] que estão sendo reinventadas com base em novas tecnologias, vigilância, fronteiras e tecnologias [...]" (Graham apud Farías 2010b, p. 203).

Para dar conta das conexões que configuram dois lugares em ação - Arena no Morro (Figura 1) e Museu do Amanhã (Figura 2) -, são exploradas

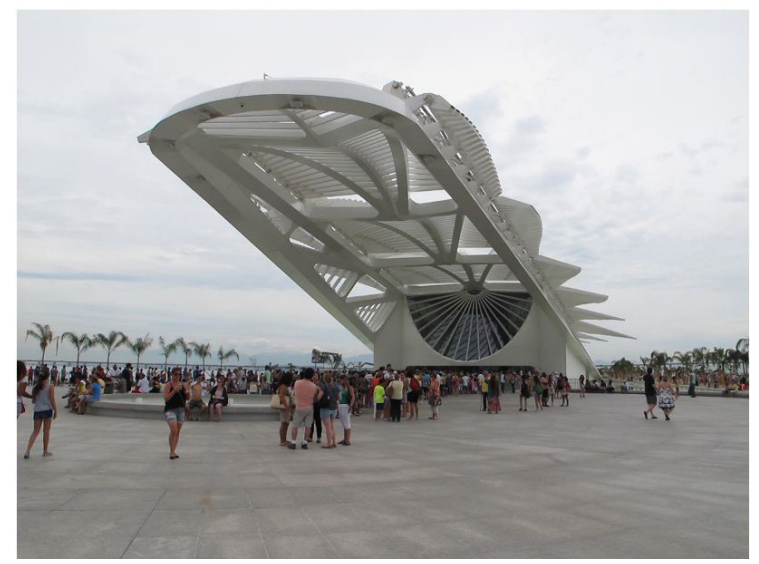

Figura 2 - Museu do Amanhã (vista externa) Fonte: Acervo dos autores (2015). 
adicionalmente outras proposições, tais como o corpo como interface que aprende (Latour, 2008), o conhecimento situado ou saberes localizados (Haraway, 1995), as políticas ontológicas (Mol, 2008) e as espacialidades (Law \& Mol, 2000).

\section{Abrindo a "Caixa de Ferramentas"}

Apresentam-se aqui algumas noções que figuram como "ferramentas" que permitirão operar as análises exploratórias para configurar nossos lugares em ação.

Para começar, edifícios e lugares devem ser entendidos como interfaces que aprendem - enunciado que guarda grande ressonância com a afirmação latouriana de que o corpo é uma interface que aprende a ser afetada por muitos elementos e deixa uma trajetória dinâmica, permitindo aprender a registrar e ser sensíveis a tudo aquilo de que é feito o mundo (Latour, 2008). De modo análogo, edifícios e lugares seriam proposições articuladas que emergem de processos de mediação, envolvendo entidades "técnicas", "políticas" e "econômicas". Corpos, edifícios e lugares seriam, assim, agentes de transformação que se recriam continuamente e nos quais nada se propaga sem transformação ou reapropriação local.

Edifícios e lugares performam também conhecimentos situados, no sentido de que sua produção/construção se dá em condições que podem ser descritas e localizadas (Law \& Mol, 2000), envolvendo os diferentes materiais que participaram dessa fabricação - inclusive os corpos dos arquitetos. Seguindo Latour (2008), como e quais são as diversas formas com que o corpo dos cientistas - e dos arquitetos - é envolvido naquilo que faz?

Compreender edifícios e lugares como interfaces que aprendem a ser afetadas e cuja produção é sempre local e situada, portanto marcada (Haraway, 1995), remete ao entendimento adicional de que sua construção é ontológica e política (Mol, 2008). Em outras palavras, ela produz mundo. Além disso, o termo política sublinha seu modo ativo e seu "caráter aberto e contestado" (Mol, 2008, p. 63). Estes "objetos" - edifícios e lugares - "[...] são negociados por diferentes grupos de atores, articulando simultaneamente componentes materiais e sociais da cidade" (Farías, 2010a, p. 4).

Conhecimento situado e ontologias políticas reforçam o entendimento de que corpos e lugares são transformados em suas configurações, aparências e performações; são "objetos" prontos para serem usados e sujeitos a futuras modificações, não "coisas fixas da natureza material" (Knorr-Cetina, 2001, p. 528). Aceitar essa condição amplia os horizontes topológicos para além da espacialidade euclidiana, em direção a Outras espacialidades, que se complementam, incluem, misturam e associam.

O problema das espacialidades da ciência foi tratado por John Law e Annemarie Mol (2000), que, ao questionarem a "universalidade" da ciência, formularam a pergunta: se a ciência não é "universal", onde ela se localiza? Rastreando os fatos científicos a partir dos laboratórios, formularam o argumento de que as descobertas e as teorias científicas são produzidas em lugares específicos. Os movimentos dos fatos, teorias e matérias-primas da ciência têm a ver com os Correios, com o transporte e com a qualidade das redes de dados, o que não significa que sua difusão se resuma a um problema de transporte físico. Eles precisam ser tratados como fatos quando chegam a seus destinos; precisam ser reconhecidos e estar equipados nos seus contextos: os próximos laboratórios, "o que significa que a configuração dos fatos-e-contextos deve ser mantida estável" (Law \& Mol, 2000, p. 2). Para formular esse argumento, os autores diferenciam diferentes espacialidades, a saber: euclidiana, das redes, fluida e do fogo.

A espacialidade euclidiana permite pensar que os corpos e os lugares mantêm sua singularidade

[...] em um espaço euclidiano e seu sistema de coordenadas neutro e pré-existente, que define as condições de possibilidade nas quais os objetos podem existir, exercer a identidade e a experiência de proximidade ou distância [...] (Law \& Mol, 2000, p. 2).

Por princípio, todos os objetos e os elementos que constituem a materialidade de um lugar precisam ser funcionalmente mantidos no lugar. Segundo Latour \& Yaneva (2008, p. 82), o espaço euclidiano é aquele “[...] no qual os edifícios são desenhados no papel, mas não o ambiente no qual os edifícios são construídos - e muito menos o mundo no qual eles são vivenciados".

Mas objetos e lugares se movem no espaço e no tempo. Como eles são deslocados? No espaço euclidiano, a distância percorrida e a proximidade com outros atores são determinadas por suas coordenadas cartesianas, que se alteram enquanto o objeto se move. Topologicamente, os dois argumentos estão relacionados: para produzir objetos-formas e definir o 
que se entende por continuidade no seu deslocamento, é necessária a produção, simultaneamente, das condições espaciais de possibilidade. Mas performar continuidade e identidade, ou medir a distância nos termos das coordenadas cartesianas, ou ainda definir as possibilidades das condições espaciais de subsistência dos objetos, demanda promulgar o espaço euclidiano, ou seja, fazê-lo existir. Mas a quase reificação da espacialidade euclidiana pelo senso comum pode resultar do desconhecimento do trabalho necessário para produzi-la (Law, 2000), levando a uma naturalização desse sentido.

Já na espacialidade das redes, o que importa são as relacionalidades e as conectividades. Ela emerge quando formas e objetos estáveis e singulares configuram um conjunto estável de ligações com outras entidades. Isso acontece porque objetos e elementos, materiais ou não, movem-se e circulam em outros tipos de veículos. Funcionar corretamente na estrutura incerta da espacialidade de uma rede, mantendo a estabilidade e a continuidade das formas e dos objetos, demanda outra sintaxe. Um lugar precisa que todos os objetos e os elementos que o constituem façam seu trabalho: "pedir emprestado" a luz do sol, a energia elétrica, a força e a vontade dos cidadãos e incorporá-los; criar estruturas de relações que garantam que edifícios, vias, ventos, energia elétrica, cidadãos e outras entidades sejam funcionalmente mantidos no lugar, além de estratégias para garantir a invariância sintática da rede. Como na lógica das redes move-se do espaço cartesiano para o espaço da rede, e vice-versa, é preciso associar sua promulgação com os processos de construção e com os modos de performação desse espaço.

Um lugar funcionando é um objeto ou uma "forma de rede" constante e contínua, que pode ser entendido como um conjunto fixo de coordenadas cartesianas de todos os seus elementos fixos. Pessoas, veículos, água e energia se deslocam no espaço cartesiano. 0 que precisa se manter estável são as posições relativas sintáticas e funcionais das outras entidades que performam ou contribuem para a coerência da cidade - e para seu movimento. Manter a configuração estável demanda muito esforço e trabalho. Mover qualquer coisa entre dois lugares demanda muito trabalho para assegurar que sua forma seja mantida e, assim, garantir a comunicação entre ambos. Por isso, é importante compreender como viajam as máquinas e as maquinações.
Nos séculos XV e XVI, os navios portugueses moviam-se relativamente juntos no trajeto Lisboa-Calicute-Lisboa. Eles configuravam uma rede de dupla produção, cujo funcionamento tem a ver com o "móvel imutável" (Latour apud Law \& Mol, 2000): aquilo que se move mantendo sua forma imutável pertence ao espaço de rede ou sintático, enquanto a mobilidade - atributo cartesiano - torna-se possível pela imutabilidade da rede. 0 móvel imutável lida com duas espacialidades: com o espaço euclidiano, no qual um navio permanece imóvel quando está atracado no porto, mas se move quando vai para o mar, e com o espaço de uma rede, no qual o navio é imutável.

Segundo Latour (apud Law \& Mol, 2000), é preciso considerar as duas espacialidades interligadas. Em uma primeira aproximação da embarcação, ela não se move no espaço. "É a interferência entre os sistemas espaciais que proporciona ao navio suas propriedades especiais" (Law \& Mol, 2000, p. 5). Os navios formam redes invariáveis e materialmente heterogêneas, imutáveis, porque, pelo menos em teoria, seus diversos componentes prendem-se uns aos outros em seus lugares.

Uma grande rede (com seus ventos, suas estrelas, seus comerciantes e os seus príncipes) implica um espaço de rede que torna possível a mobilidade imutável de um objeto - como um navio Português viajando de Lisboa para Calicute (Law \& Mol, 2000, p. 3-4).

Mas, se durante o deslocamento, por algum imprevisto, for necessário trocar um ou mais componentes do navio, ele se transforma em um móvel mutável.

Com a associação da metáfora da rede, que constitui um laboratório - e que também precisa ser transportado -, com a noção de móvel imutável - o que se move através do espaço regional, mantendo a sua forma -, pode-se entender "o global" como uma rede para o transporte de formas invariáveis: informação, descobertas científicas, artefatos tecnológicos.

A espacialidade fluida surge como uma terceira possibilidade para imaginar o global, pois ideias, fatos, informações e tecnologias podem se espalhar com maior ou menor fluidez. A globalização é sobre essa fluência dos movimentos que acontecem quando existe menos controle. A fluidez diz respeito a coisas que são adaptáveis, que mudam de forma e assumem o formato de seus contextos, como os hotéis de uma rede internacional que se espalha pelo mundo. Nela nada é 
fixo: cada unidade muda de forma conforme o lugar, a região e a cultura; alguns componentes quebram e são substituídos; outros inicialmente não previstos são adicionados. A variação das configurações das diferentes unidades de uma rede de hotéis a transforma em um móvel mutável: em lugares distintos, o hotel é o "mesmo objeto" e um "objeto diferente". Uma rede de hotéis muda de forma no espaço euclidiano e opera diferente em cada lugar onde é implantada (Law \& Mol, 2000). Essa característica variável na forma e no conteúdo permite que se "mova" para tantos lugares no mundo, mesmo não sendo uma forma invariável na rede ou no espaço euclidiano. Mas aqui é preciso muita atenção, porque a mutabilidade também se estende para o uso de cada unidade e para os serviços e as acomodações ofertadas - a qualidade e a pureza da água variam de uma região para outra -, mas não para sua "materialidade", e isso torna cada unidade um imóvel mutável. Em alguns, a água distribuída atende a critérios internacionais; em outros, não. 0 mesmo acontece com os sistemas de coleta e tratamento de esgoto, de ar-condicionado, com a qualidade, estabilidade e regularidade de fornecimento de energia elétrica, TV a cabo e Internet. São serviços e sistemas que dependem do sucesso das condições locais de oferta, dos cuidados de manutenção, da qualidade, do esforço de trabalho, das políticas locais, regionais, nacionais e internacionais de economia e turismo. Assim, em lugar de objetos de uma rede falha, pode ser mais útil pensar nas suas unidades como objetos que fluem, mas mantêm sua forma em diferentes lugares e configurações de rede. Assim, cada unidade também é um imóvel mutável. Aqui se tem uma espacialidade fluida com outro tipo de invariância da forma: são as conexões que fazem uma forma invariável de fluido mudar de modo gradual e incremental. As ligações mudam lentamente seu caráter. As unidades não são nem funcionam exatamente iguais. Suas funções e formas são diferentes e se modificam, na medida em que peças e sistemas são substituídos, modificados ou acrescentados. A forma gradual de adaptação, instalação, gestão e manutenção das unidades em uso permite que cada uma continue operando sem grandes pausas ou interrupções. A invariância da forma é garantida por um processo gradual de adaptação com fluxo mais ou menos suave. Ela é fixada por um deslocamento que resiste à ruptura e se mantém constante durante algum tempo. Em lugar de impor projetos rígidos, os projetistas e os gestores das unidades do hotel precisam conviver com sua variabilidade. As alterações introduzidas na instalação e na operação de cada unidade indicam que projetistas e gestores também performam com a fluidez de um espaço fluido, cujo interior mantém certa constância de forma.

Mas a fluidez não esgota as metáforas espaciais para pensar o global. Law \& Mol (2000) propõem a espacialidade do fogo, na qual a continuidade depende da descontinuidade; é a presença da ausência, o movimento ou deslocamento daqui para ali. A topologia do fogo tem a ver com "[...] formas estáveis criadas em padrões de relações de alteridade conjunta [...]" (Law \& Mol, 2000, p. 8), segundo três atributos de constância da forma ou continuidade: (a) como um efeito da descontinuidade; (b) pela presença e ausência de alteridade; e, para casos específicos, (c) como se fosse feito do brilho de uma estrela como padrão de diversidade simultânea de ausência e presença.

A perfuração do solo para a ampliação do metrô do Rio de Janeiro é um bom exemplo. 0 projeto de uso do "Tatu" - equipamento de perfuração - baseou-se: em informações geológicas e das concessionárias de infraestrutura urbana; nos projetos das redes subterrâneas e das fundações dos edifícios existentes; no número de operários e técnicos envolvidos nas operações. Foram analisados os riscos e previstas medidas para garantir a integridade e a segurança dos edifícios existentes, moradores, operários e técnicos, com a mínima interferência possível no dia a dia dos bairros que seriam servidos. Antes de perfurar, os projetistas analisaram o conjunto de informações sobre o solo, lençol freático, redes de infraestrutura e fundações dos edifícios. Consideraram as normas vigentes para garantir a segurança dos edifícios, ruas, moradores e funcionários. Todos os procedimentos foram descritos e detalhados em um caderno de encargos: posição e velocidade de operação foram previstos, de modo a reduzir o risco de acidentes, nível de ruído e trepidação nos edifícios e ruas.

Quando o Tatu começou a perfurar, os responsáveis pela obra tiveram que "[...] ir para outros lugares ...que estavam fora da página [...]" (Law \& Mol, 2000, p. 8) e procurar outras conexões não calculadas no projeto. Apesar dos cuidados, a perfuração não funcionou como o previsto e recrutou outros atores. Crateras se abriram em alguns trechos de ruas de Ipanema, dificultando a vida e a mobilidade de moradores e veículos. Foi preciso reavaliar os riscos de desabamento, interromper o fornecimento de água, gás e energia, contratar obras 
de reforço e reparo dos danos provocados. Também foi necessário interromper a perfuração. Os cálculos e as análises prévias não foram suficientes. Operários adoeciam devido aos efeitos de vazamentos de água, esgoto e gás; outros corriam riscos de acidentes, como desabamentos, inundações e choques elétricos. Moradores tiveram que se mudar temporariamente ou passaram mal.

Como a performação é uma associação complexa entre o que está presente no projeto e o que não está, o problema não se limita a lidar com uma parte materialmente heterogênea da rede. Existe uma irredutível descontinuidade entre o que está e não está no papel, que não se pode perder de vista. A velocidade de perfuração depende do que estava ausente, isto é, desabamentos, interdições pela Defesa Civil, Corpo de Bombeiros, Ministério da Saúde ou manifestações populares. Seu significado depende de torná-lo ou não ausente: na rede de relações do projeto impresso elaborado por um grupo de profissionais em um escritório não existe espaço para acidentes, desabamentos ou interdições, que podem ser pensados como interrupções ou lapsos entre presença-ausência e ausência-presença. Essa é a chave para o que é distintivo na estabilização relativa da performance desse objeto: a velocidade da perfuração atinge seu significado, em parte, devido a essa oscilação ou movimento entre uma relação simultânea de presença e ausência. Os outros elementos do projeto operam de modo semelhante. A velocidade do Tatu élimitada pela necessidade de reduzir o risco de acidente. Mas por que é necessário aumentar a velocidade do Tatu? A resposta tem a ver com os Jogos Olímpicos de 2016 e com os custos: se a velocidade aumentar muito, o Tatu pode ficar soterrado em um desabamento de proporções catastróficas. Na lista de Outros associados que estão ausentes (da folha de papel) e presentes (eles têm que estar lá), agora estão incluídos os Jogos Olímpicos e as doenças e acidentes dos operários e moradores. Argumentos análogos aplicam-se a outros componentes do projeto: definição do percurso, localização e capacidade das estações, sistema de transporte vertical até a superfície conduzindo para o reino da política burocrática (quais bairros serão atendidos, qual a relação entre o investimento e a previsão de retorno). Todos os termos do projeto alcançam sua estabilidade em virtude da simultânea ausência e presença de outros materiais e situações, ou seja, a estabilidade emerge da continuada performação das descontinuidades (que, por essa peculiaridade, também podem ser entendidas como continuidades) com esses Outros materiais e contextos. Isso se aplica aos componentes e ao projeto todo, que toma a forma de um padrão de brilho estelar. Várias alteridades são associadas a uma presença central. Existe uma ida e uma volta. As entidades e os mundos irredutíveis em que eles estão localizados são mantidos juntos - e para além -, enquanto a forma fogo se mantém no lugar.

Como qualquer edifício ou lugar é global - a globalidade está inscrita nele--, abre-se a possibilidade de explorar sua versão do global: como ele inclui Outros.

\section{Arena do Morro e do Museu do Amanhã: lugares em ação}

Para demonstrar como as espacialidades se produzem e se misturam nos lugares em ação, recorre-se ao processo de fabricação da Arena do Morro e do Museu do Amanhã, parafraseando o texto que fecha o artigo de Law \& Mol (2000). Os projetos do Ginásio Poliesportivo Arena do Morro e do Museu do Amanhã foram construídos, respectivamente, em terrenos existentes e localizados: ao lado da Escola Estadual Senador Dinarte Mariz, na rua Camaragibe, s/n, na favela Mãe Luiza, em Natal, e no Píer da Praça Mauá, zona portuária do Rio de Janeiro. Assim, eles são locais ou regionais e performam móveis imutáveis.

Sua concepção mobilizou equipes internacionais e interdisciplinares: a Arena do Morro foi concebida a partir de uma parceria da Prefeitura Municipal de Natal e do Governo do Estado do Rio Grande do Norte com duas entidades que atuavam na Mãe Luiza (Centro Sócio-Pastoral Nossa Senhora da Conceição e a Fundação Ameropa) ${ }^{1}$. 0 projeto de arquitetura foi elaborado pelo o escritório suíço Herzog \& De Meuron²; já o projeto executivo foi desenvolvido

\footnotetext{
${ }^{1}$ Organização não governamental vinculada a uma empresa suíça de grãos, fertilizantes, petroquímica e metais, criada para apoiar projetos humanitários, educacionais e agrícolas em países em desenvolvimento, parceira da Prefeitura Municipal de Natal no Passo da Pátria e na favela Mãe Luiza. Fonte: The Ameropa Foundation (2016) e Prefeitura Municipal (Natal, 2011).

${ }^{2}$ Escolhido pela Fundação Ameropa, sediado na Antuérpia, com filiais em Hamburgo, Londres, Madri, Nova Iorque e Hong Kong. Participaram da equipe de projeto: Jacques Herzog e
} 
em parceria com o escritório local Plantae. O Museu do Amanhã resultou de uma parceria entre a Prefeitura da Cidade do Rio de Janeiro, o Banco Santander e a Fundação Roberto Marinho. 0 projeto foi elaborado pelo escritório espanhol Santiago Calatrava, enquanto o projeto executivo de arquitetura foi desenvolvido em parceria com o escritório local Ruy Rezende Arquitetura (RRA), além de outras empresas e consultores. Sua elaboração demandou diversas idas e vindas de desenhos, documentos e membros das equipes de projeto para participar de negociações com os promotores e com os colaboradores locais.

\section{Assim, eles também são globais.}

Os projetos e os documentos foram transportados sem alterações entre os escritórios europeus e os brasileiros. Eles performaram dispositivos móveis imutáveis. Mas as circunstâncias em que eles foram impressos e lidos pelas respectivas equipes técnicas fizeram com que fossem sutilmente reconfigurados. 0 mesmo, mas também diferente, o que significa que eles também performaram móveis mutáveis.

Mas a produção dos dois projetos inclui (e também esconde) a Terra na forma dos materiais utilizados na elaboração dos desenhos e dos documentos, nos odores e sabores dos alimentos e bebidas que as equipes de projeto ingeriram durante sua elaboração, nos materiais utilizados pelas equipes locais para imprimir e visualizar os desenhos e os documentos recebidos, assim como para desenvolver os projetos executivos. Só os deuses sabem o que mais pode estar incluído em projetos como esses. Então, os projetos também existem no espaço do fogo ou da alteridade conjunta. Eles também performam imóveis mutáveis e compartilham as quatro espacialidades.

Eles são interfaces que aprendem, e sua existência tem a ver com as conexões entre os edifícios e lugares em ação, com o conhecimento situado, com as ontologias políticas - que têm relação com o modo como o narrador opera sua seleção e exerce sua parcialidade (Haraway, 1995) - e com as espacialidades. Quando se fala de edifícios e lugares em ação, refere-se a uma materialidade situada, a interfaces que aprendem e que, por sua vez, desdobram-se em outros atores, tais

Pierre de Meuron (autores), Ascan Mergenthaler (responsável pelo projeto) e Markus Widmer; equipe Tomislav Dushanov (associado, diretor do projeto), Maria Vilela (coordenadora do projeto), Diogo Rabaça Figueiredo, Daniel Fernández Flores, Stephen Hodgson, Melissa Shin, Kai Strehlke e Edyta Augustynowicz (tecnologias digitais). como solo, topografia, paisagem natural e edificada, morfologia dos edifícios, cores, texturas e arranjos dos materiais de revestimento, vegetação etc. Mas edifícios e lugares em ação também contêm (e escondem) diversas ações que interferem em sua performance.

Na conferência de encerramento do VII Projetar, realizada em 2015, o arquiteto Tomislav Dushanov (Figura 3) falou sobre a concepção do projeto Arena do Morro. 0 palestrante enfatizou: a importância do processo participativo, da compreensão do sítio e dos valores culturais dos habitantes da comunidade Mãe Luiza; a parceria com os construtores e o cuidado com os detalhes, alguns testados em escala real; a escala, a leveza, a configuração e a permeabilidade do edifício; a cor, a iluminação e a amplitude dos espaços internos; a qualidade construtiva, o esmero e o rigor dos detalhes construtivos (evidências da sabedoria que foram explorados, assim como o clima e a paisagem local).

As matérias Herzog \& De Meuron projetam a arena do Morro, um ginásio cultural e poliesportivo em bairro carente de Natal (Vieira \& Dantas, 2014) e Herzog \& De Meuron: Arena do Morro, Natal (Herzog \& De Meuron, 2014), publicadas em revistas técnicas de circulação nacional, são ilustrativas do reconhecimento da qualidade do projeto, como se pode perceber na citação recrutada de uma delas:

A inauguração [...] é o passo inicial de uma proposta urbana que pretende prover a comunidade de espaços coletivos de recreação, esporte, cultura e educação. o equipamento é o centro de um eixo previsto para atravessar o bairro na

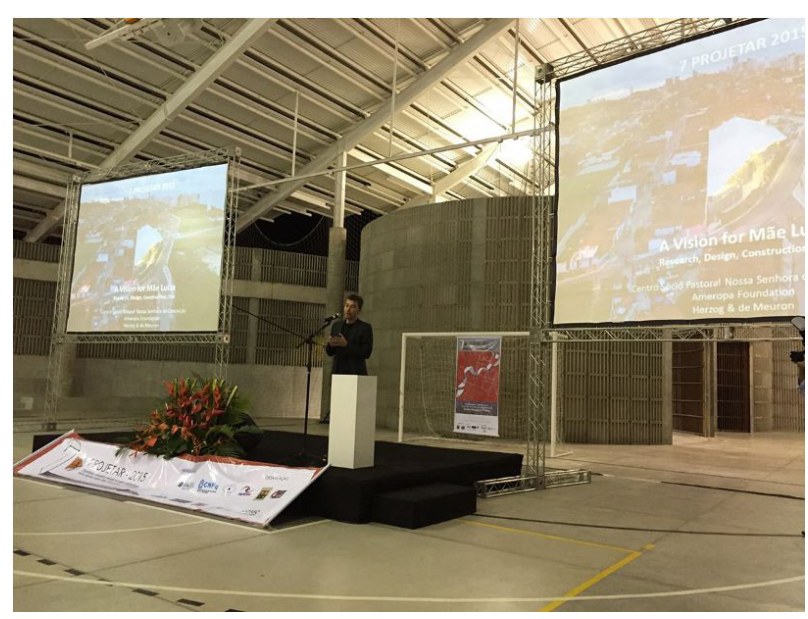

Figura 3 - Arena do Morro (palestra de Tomislav Dushanov no VII Projetar) Fonte: Acervo dos autores (2015). 
direção do mar, e, a despeito da simplicidade dos materiais - todos aparentes -, sua excelência reside no rigor do detalhamento construtivo e no caráter ambíguo, meio monolítico, meio permeável, do projeto. qualificado pela brisa e transparência contida (Herzog \& De Meuron, 2014, p. 1).

O texto disponível no site do escritório é elucidativo do processo coletivo produzido no trabalho comunitário envolvendo habitantes de Mãe Luiza, profissionais de projeto, construtores, financiadores, entidade religiosa, organização não governamental e órgãos públicos.

Mãe Luiza não é uma típica "Favela" - sua identidade e caráter foram configurados em função de seu cenário natural único e da criatividade das pessoas desta forte comunidade. [...] A estrutura existente do antigo ginásio [...] define o ponto de partida do projeto. Sua geometria foi extrudada sobre toda a área do edifício, configurando uma grande cobertura cuja forma foi limitada e definida pelos limites o terreno. A cobertura introduz uma nova escala em Mãe Luiza, ao mesmo tempo em que expande a abordagem tradicional de uso de uma cobertura generosa para criar amplos espaços públicos no Nordeste do Brasil. Torna-se um símbolo da Comunidade. Sob o teto, o chão configura uma paisagem local de alvenaria que segue a topografia existente. Os degraus das arquibancadas traçam as linhas de contorno da área descoberta e da sala polivalente, das salas de dança, e dos espaços de apoio que foram localizados no centro. Uma parede ondulante e independente define $o$ perímetro interno, seguindo o contorno dos lugares que circundam a quadra de esportes e a forma circular das salas autônomas e com maior privacidade. Os volumes circulares salientam o carácter comum desses espaços e das atividades internas [Figura 4]. [...] A estrutura é simples e aberta, refletindo e respondendo à disponibilidade de materiais e métodos de construção locais. A cobertura foi montada com painéis padronizados de alumínio corrugado e isolado [...] instalados com frestas abertas e sobrepostas que permitem a passagem da luz e do ar, mas que evita a passagem da água. A parede curvilínea e baixa é feita de blocos concretos especificamente desenvolvidos e fabricados localmente. As aletas de bordas arredondadas e verticais de cada bloco [...] criam vários níveis de transparência e de privacidade. Tanto a cobertura quanto a parede são membranas permeáveis e translúcidas que permitem que a brisa do mar flua através do edifício e a saída do ar quente, além de filtrar a luz natural do dia, transformando toda a edificação em uma única peça com diversas gradações de luz e sombra. À noite o efeito se inverte e o edifício revela as atividades de internas como se fossem uma brilhante lanterna gigante. 0 ginásio é um edifício permeável, totalmente climatizado naturalmente que transforma e traduz o impacto do seu ambiente natural e urbano em um uso público voltado para atividades esportivas, de lazer e culturais. Seu sucesso final vai depender de sua programação diária e noturna e da sua aceitação pelas pessoas de Mãe Luiza (Herzog \& De Meuron, 2016)

As matérias pesquisadas e o texto dos autores do projeto indicam tratar-se de um edifício ou lugar desejado, pensado, projetado e vivenciado com intensidade. 0 texto traduz o processo de concepção e de diálogo com a comunidade e com o entorno. A inexistência de evidências de vandalismo é indicativa de que os arquitetos, que não cobraram honorários, traduziram com maestria e sensibilidade os desejos do coletivo Mãe Luiza, um bairro de periferia carente de investimentos. 0 edifício explora, aproveita e potencializa as condições ambientais: oferece sombra,

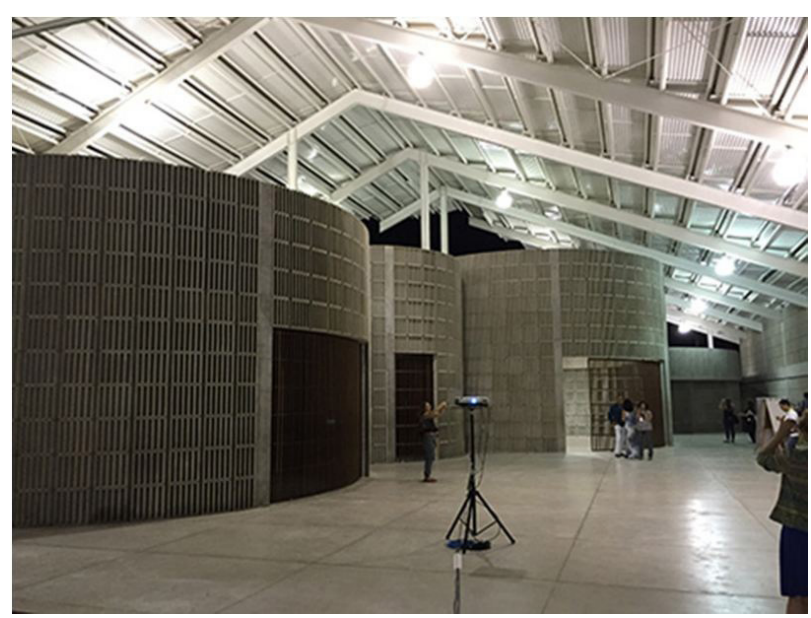

Figura 4 - Arena do Morro (vista da Quadra e das Paredes Curvas) Fonte: Acervo dos autores (2015). 
filtra o excesso de luz natural e suas paredes e cobertura vazadas deixam fluir a brisa fresca do mar. 0 apuro dos detalhes e o acerto na escolha dos materiais e texturas transformam a Arena do Morro em uma pérola cultivada com muito carinho e respeito. É um exemplo bem-sucedido de placemaking (Dutton, 2000; Castello, 2007)

A ausência de marcas de vandalismo, a conservação e a limpeza da Arena do Morro são indícios da sua aprovação e apropriação, apesar da restrição de acesso ao local, considerado perigoso por muitos motoristas de táxi que se negam a subir até aquela região. Durante a conferência de Dushanov, foram mobilizados policiais fortemente armados e, já na chegada, os visitantes foram orientados a não sair dos limites do terreno. Se os policiais forem recrutados sempre que outros grupos visitem a Arena do Morro, a espacialidade do fogo estará se fazendo presente.

Já o Museu do Amanhã tem sido tratado pelo marketing como a "cereja do bolo" do Porto Maravilha, ambicioso projeto de renovação urbana da zona portuária. 0 museu foi projetado e construído com recursos arrecadados pela Prefeitura com as CEPACS - Certificados de Potencial Adicional de Construção, adquiridos por investidores imobiliários interessados em construir acima do gabarito definido pelo zoneamento da região portuária - e complementados com patrocínio (Carneiro, 2015).

A operação de troca envolveu os interesses da atual administração municipal e dos investidores, produzindo algumas polêmicas: a implosão do elevado da Avenida Perimetral e o desaparecimento de seis vigas de aço especial com 40 metros de comprimento e 20 toneladas; o processo de gentrificação (Montaner \& Muxí, 2014, p. 144) que vem ocorrendo nos bairros da Saúde, Gamboa e Santo Cristo; e a escolha do escritório responsável pelo projeto. Em vez de promover um concurso público, a Prefeitura optou por formalizar parceria com a Fundação Roberto Marinho, a quem delegou a contratação do projeto - o escritório espanhol Santiago Calatrava Architects \& Engineers -, cujo custo não foi informado.

O Museu do Amanhã é um dos projetos que estão sendo concebidos na zona portuária da cidade do Rio de Janeiro por "arquitetos-estrela" (Montaner \& Muxí, 2014, p. 211). A cidade, em função de grandes eventos internacionais como a Copa do Mundo em 2014 e os Jogos Olímpicos de 2016, está passando por grandes processos de tematização e museificação, com a invasão de símbolos isolados e agressivos que desprezam o espaço público circundante (Montaner \& Muxí, 2014, p. 153). Uma matéria publicada na Veja Rio (Pessoa, 2015) descreve o processo de projeto e sua aura de placemarketing (Rheingantz et al., 2005; Castello, 2007):

A principal obra cultural em construção no Brasil nasceu bem longe daqui. 0 [...] mais extravagante edifício da região portuária do Rio [...] começou a tomar forma nos Alpes suíços. Foi em um chalé plantado em meio à paisagem bucólica e arrematada por montanhas cobertas de neve que o arquiteto espanhol Santiago Calatrava [...] concebeu os primeiros traços do projeto, orçado em 215 milhões de reais. Uma vez definidas as linhas gerais, os demais desenhos foram feitos em outra paisagem, pelo próprio Calatrava: sentado à beira do Píer Mauá, no exato local onde o prédio de 18.000 metros quadrados está sendo erguido. Um dos mais brilhantes expoentes da chamada arquitetura-espetáculo [...] Calatrava levanta prédios que mais parecem imensas obras de arte. [...] "Foi uma honra projetar esse museu, porque não se trata apenas de erguer um prédio, e sim de criar um marco da revitalização de uma região importante da cidade. Ele será, ao lado do belo Museu de Arte do Rio, uma âncora cultural na Praça Mauá" [...] (Pessoa, 2015, p. 2).

0 texto disponível no site do escritório de arquitetura reforça o protagonismo do autor e da obra:

A forma do Museu e de seu jardim circundante configuram a parte central do Porto Maravilha - o maior projeto de desenvolvimento urbano do país e um dos compromissos de revitalização urbana que a Prefeitura da Cidade do Rio de Janeiro fez durante sua bem sucedida campanha para sediar os Jogos Olímpicos de 2016. A operação urbana do Porto Maravilha engloba a revitalização, a reabilitação e o desenvolvimento socioeconômico de uma área de 5 milhões de $\mathrm{m}^{2}$, com a introdução de um novo padrão de serviços urbanos, a implementação de coleta seletiva de lixo, a eficiente iluminação das ruas, a construção de calçadas e ciclovias, bem como o plantio de 15.000 árvores. 
A revitalização da Zona Portuária do Rio de Janeiro vai reintegrá-la com o centro da cidade. As novas instalações culturais como o Museu do Amanhã farão dela uma das áreas mais atraentes da cidade. Respeitando e complementando os monumentos históricos vizinhos, como o Mosteiro de São Bento do Rio de Janeiro, o envelope do Museu é limitado a uma altura de $18 \mathrm{~m}$ acima do píer (Santiago Calatrava Architects \& Engineers, 2015).

A postura do arquiteto, dos gestores e dos processos de concepção busca afirmar a sustentabilidade de um objeto que é insustentável pela forma, pois não garante abrigo contra o sol inclemente, contra as chuvas que costumam castigar a cidade, com suas aberturas seladas que bloqueiam as brisas frescas e tornam o edifício dependente de um sistema mecânico de controle de temperatura e umidade do ar. $\mathrm{O}$ discurso inverte o entendimento de edifício sustentável ao delegar sua dita sustentabilidade a dispositivos tecnológicos acoplados ao edifício - uso da água do mar para o sistema de arrefecimento da temperatura interna, instalação de brises móveis na fachada que servem de suporte para as placas fotovoltaicas do sistema de captação da energia solar. 0 edifício e o projeto de paisagismo pouco dialogam com o lugar. 0 piso das áreas externas em granito e a pouca arborização contribuem para o desconforto dos visitantes, que formam as extensas filas no acesso ao museu. As dimensões reduzidas do "parque ao redor do perímetro do cais" restringem as possibilidades de os visitantes se apropriarem do local para usufruir da paisagem da Baía de Guanabara (Figura 5).

A redundância de adicionar mais água perto do mar aumenta a umidade do ar. 0 espelho d'água apresenta algumas sujidades que alteram a qualidade e a coloração da água, cuja evaporação deve contribuir para acelerar a oxidação da estrutura metálica (Figura 6). Com o tempo, a poluição e as chuvas, o visual será previsivelmente diferente. Com menos de dois meses de operação, a brancura da estrutura metálica já apresenta sinais de poluição do ar e de corrosão. Uma falha nos dispositivos de segurança do sistema elétrico durante a construção provocou a morte de um operário - eletrocutado com a energização de uma estrutura metálica - e resultou no embargo das obras pelo Ministério do Trabalho e Emprego (ARCOweb, 2015).

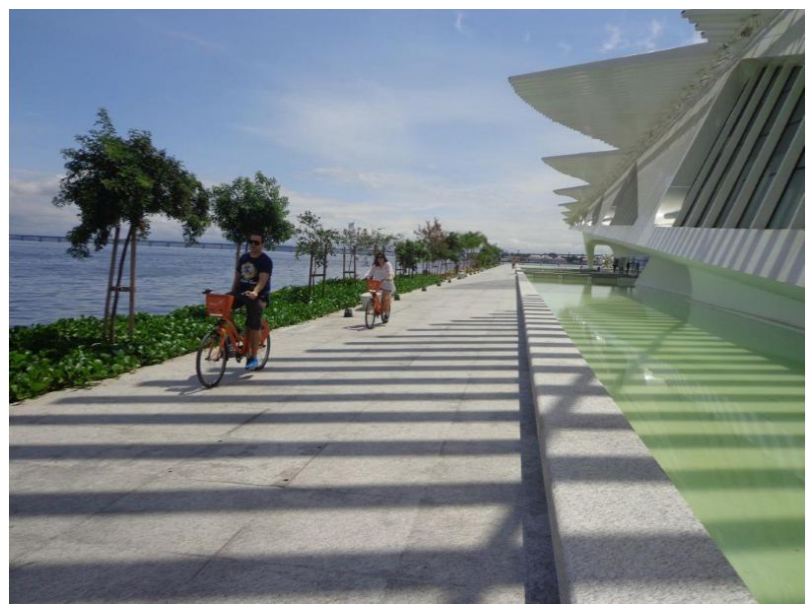

Figura 5 - Museu do Amanhã (vista do "parque") Fonte: Acervo dos autores (2016).

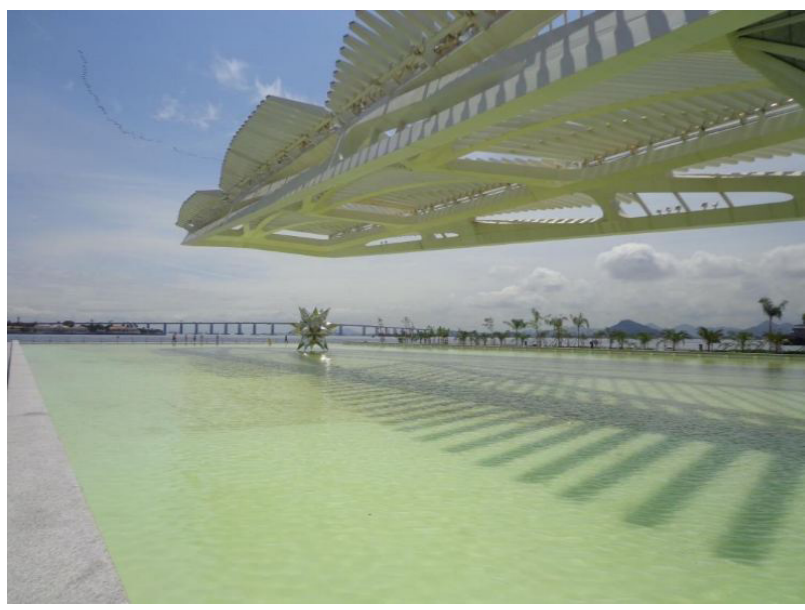

Figura 6 - Museu do Amanhã (vista do lago, com a Baía da Guanabara ao fundo) Fonte: Acervo dos autores (2016).

Um dos autores deste artigo relata assim sua primeira visita à Praça Mauá e ao Museu do Amanhã:

Movido pela curiosidade aproveitei uma manhã nublada de 29 de dezembro para visitar o Museu do Amanhã sem sofrer as agruras do sol escaldante do verão carioca. Na chegada, o esplendor da vista da Praça Mauá sem o elevado da Perimetral é impactante. Na medida em que me aproximei do museu, me misturei com a horda de curiosos por conhecer as entranhas do grande esqueleto albino plantado no píer pela dupla midiática Paes-Calatrava. No trajeto me imaginei sendo engolido pela boca gigantesca de um esqueleto de crocodilo albino [Figura 7]. [...] A impressão inicial foi de uma embalagem descartável para um conteúdo que poderia 
ocupar o edifício da Estação Leopoldina, ou ainda um dos tantos existentes nas imediações da praça Mauá. Além da evidente economia de recursos o Pier poderia ser transformado em um lugar público para usufruir a beleza da paisagem da Baia de Guanabara. Um lugar aberto, com muita sombra, grama e vegetação. E, também, sem o inexplicável espelho d'água, uma vez que a Baía da Guanabara já tem água de sobra (Rheingantz, 2015).

Diferentemente de sua dispendiosa embalagem, que tenta, inutilmente, competir com a paisagem natural e de sua localização inadequada, a proposta do museu é sedutora. Duas escadas laterais dão acesso a um girau que desemboca em duas galerias laterais que se parecem com corredores de imensos formigueiros brancos, tal a profusão de curvas, ângulos e arestas. No centro, os módulos que abrigam o conteúdo do museu: 0 auditório ocupa uma imensa esfera preta, seguido de módulos permeáveis com conteúdos interativos e virtuais. Ao final, uma

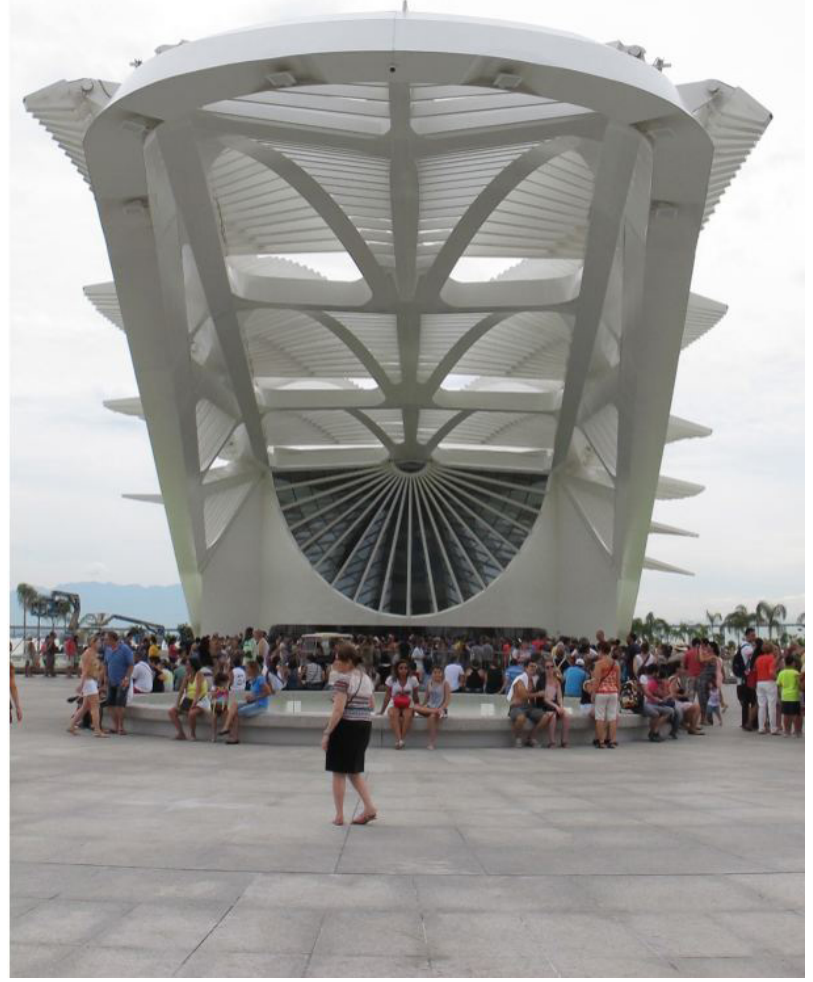

Figura 7 - Museu do Amanhã (na "boca do crocodilo") Fonte: Acervo dos autores (2015). grande vidraça descortina e delimita a vista da paisagem da Ilha Fiscal e de Niterói [...]. A descida se dá por duas rampas laterais nas quais chama a atenção a presença da maresia que embaça os vidros [Figura 8]. 0 problema se repete nas galerias laterais do piso superior [...]. À saída do museu uma ampla varanda lateral dá acesso ao espelho d'água e ao "parque", de onde se descortina uma vista que se torna mais deslumbrante na medida em me aproximo da borda do Pier (Rheingantz, 2015).

Ao retornar à Praça Mauá me deparo com a vista do Morro e Mosteiro de São Bento e dos edifícios do Arsenal de Marinha maculada por um aglomerado de edifícios que lembram "verrugas urbanas" [Figura 9]. No trajeto imaginei o desconforto das pessoas que formam as filas intermináveis sobre pisos que irradiam o calor e o desconforto produzidos pela da radiação solar. Expelido do grande esqueleto, confirma-se a impressão inicial de desperdício de dinheiro com mais um projeto que não contribui para

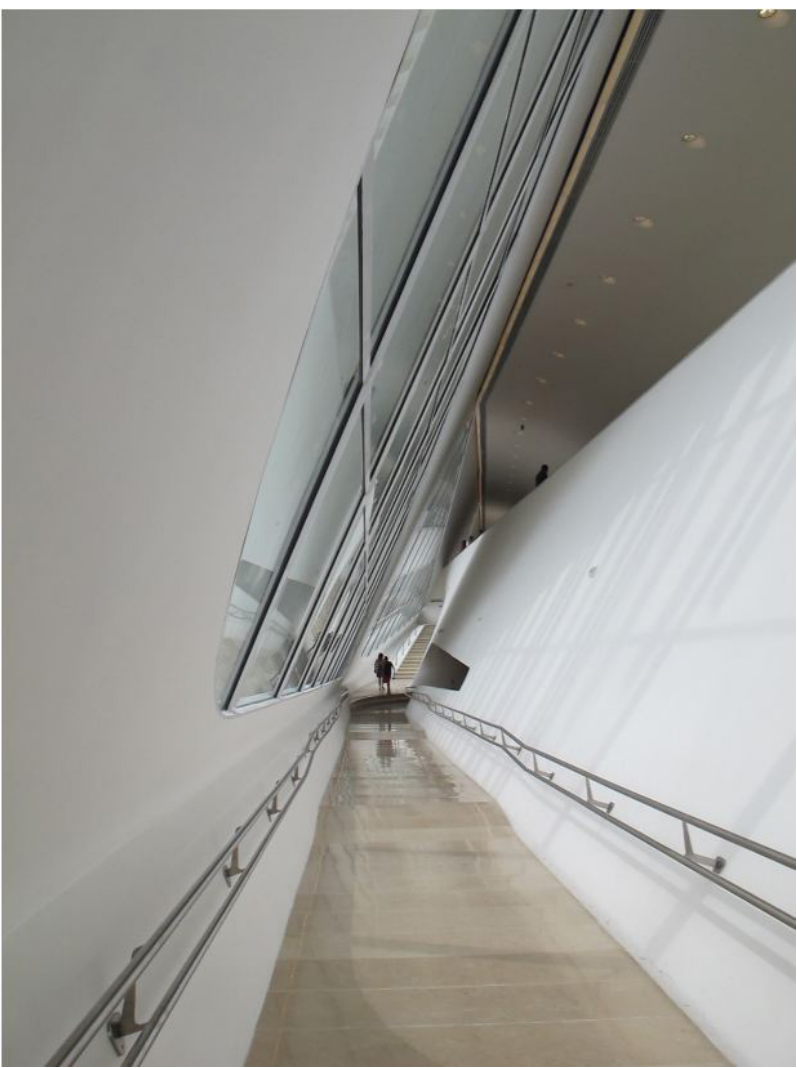

Figura 8 - Museu do Amanhã (rampa de descida) Fonte: Acervo dos autores (2015). 


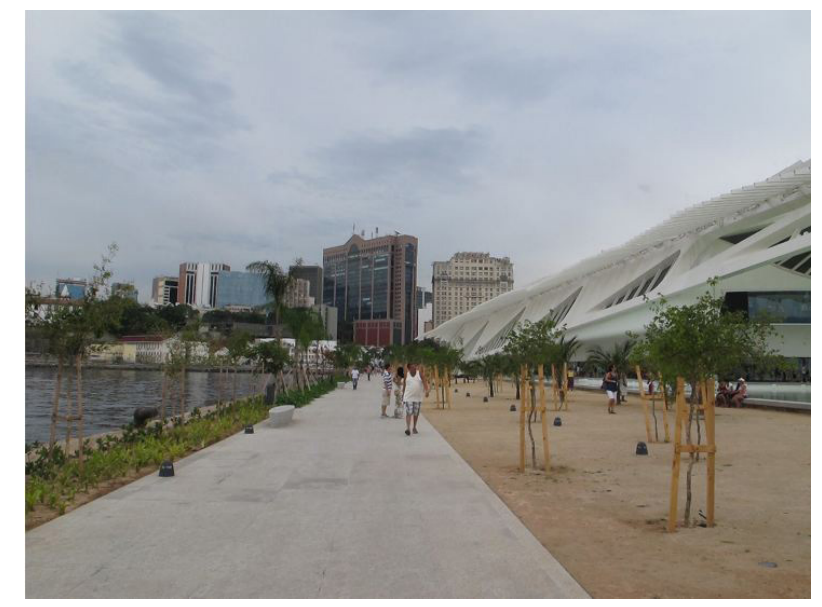

Figura 9 - Vista do Mosteiro de São Bento e das "Verrugas Urbanas" Fonte: Acervo dos autores (2015).

qualificar uma paisagem que segue maravilhosa apesar dos grandes e dispendiosos esforços em contrário (Rheingantz, 2015).

Mas as críticas e os elogios se equivalem. Propostas institucionais e ações do governo estão sendo realizadas para incentivar o uso e a apropriação do Museu do Amanhã e da Praça Mauá, bem como para dar suporte e manter suas estruturas ativas. 0 número de visitas ao museu e de frequentadores das diversas atividades culturais que se produzem naquele lugar é indicativo da sua aceitação por uma parcela da população de residentes e de turistas. 0 acesso público e os serviços de transporte - inclusive com uma linha de VLT - são pontos positivos.

Considerando as dimensões ontológicas de suas espacialidades, os processos de fabricação da Arena do Morro e do Museu do Amanhã podem ser entendidos como lugares em ação que não podem ser reduzidos àquilo que a leitura deste artigo sugere que eles "sejam" ou "significam".

\section{A título de conclusão}

As traduções desses dois lugares em ação evidenciam as diferentes ontologias políticas de seus processos de modelação, materialidades e performances. A Arena do Morro "germinou" de um processo dialógico envolvendo atores humanos e não humanos - entorno edificado, materiais de construção, clima e geografia local - em um mesmo fio condutor - o desejo de contribuir para a construção de um futuro melhor para Mãe Luiza. Sua vitalidade e naturalidade estão evidentes ao longo de todas as ações que nele e com ele vêm se concretizando. Em contrapartida, o Museu do Amanhã surgiu em resposta ao desejo compartilhado por dirigentes municipais e investidores interessados em produzir o símbolo de um processo excludente de renovação urbana, concebido por um arquiteto interessado em afirmar sua genialidade em um lugar qualquer. A Arena do Morro abriga atividades esportivas e culturais dos habitantes de Mãe Luiza, enquanto o Museu do Amanhã convida os visitantes a explorar a interatividade das imagens dissimuladas do mundo, "[...] na medida em que, como tais, não são capazes de revelar as relações que o constituem [...]" (Szapiro, 2009, p. 90). Ambos são lugares em ação, ou laboratórios de urbanidade, que se diferenciam em função dos movimentos de poder associados às suas ontologias políticas, do conhecimento situado e das interfaces que aprendem com seus movimentos nas diferentes espacialidades. Ambos são híbridos que se recriam mutuamente, e suas apreciações serão sempre situadas e particulares. Independente de teorias e conceitos, sua qualidade é modelada pelas performances dos movimentos e ajustes no modo como o "real" está implicado no "político" e ambos são objetos prontos para serem usados e sujeitos a futuras modificações, portanto imóveis mutáveis. Sua qualidade não se limita à nossa quase reificação da espacialidade euclidiana, que, além de naturalizar a prevalência das qualidades visuais dos lugares sem considerar as ações que neles se produzem, costuma desconsiderar que a performação é uma associação complexa entre o que está presente nos lugares e o que não está. Ela depende da estabilidade da configuração dos fatos e contextos e também precisa não perder de vista a descontinuidade entre o que está no projeto e o que não está; incluir Outros associados, que estão ausentes dos projetos, mas que têm que estar lá. Lugares em ação produzem diferentes modos de ser e habitar a cidade.

\section{Referências}

ARCOweb. (2015). Calatrava: após morte, Museu do Amanhã tem obras paralisadas. São Paulo. Recuperado em 25 de abril de 2015, de https://arcoweb.com.br/noticias/arquitetura/ calatrava-apos-morte-museu-amanha-obras-paralisadas

Carneiro, J. D. (2015). Conheça o Museu do Amanhã inaugurado no Rio de Janeiro. Recuperado em 15 de 
fevereiro de 2016, de http://www.bbc.com/portuguese/ videos_e_fotos/2015/12/151210_museu_amanha_jc_lk

Castello, L. (2007). A percepção de lugar - repensando o conceito de lugar em arquitetura-urbanismo. Porto Alegre: Propar/UFRGS.

Dutton, J. (2000). New american urbanism - re-forming the suburban metropolis. Milão: Skyra.

Fallan, K. (2008). Architecture in action: traveling with actor-network theory in the land of architectural research. Architectural Theory Review, 13(1), 80-96. http://dx.doi. org/10.1080/13264820801918306.

Farías, I. (2010a). Introduction: decentring the object of urban studies. In I. Farías, \& T. Bender (Eds.), Urban assemblages - how actor-netowirk theory changes urban studies (p. 1-24). Londres: Routledge.

Farías, I. (2010b). Interview with Stephen Graham. In I. Farías, \& T. Bender (Eds.), Urban assemblages - how actor-netowirk theory changes urban studies (p. 197-206). Londres: Routledge.

Farías, I., \& Bender, T. (Eds.) (2010). Urban assemblages how actor-netowirk theory changes urban studies. Londres: Routledge.

Guggenheim, M. (2010). Mutable immobiles: building conversion as a problem of quasi-technonogies. In I. Farías, \& T. Bender (Eds.), Urban assemblages - how actor-netowirk theory changes urban studies (p. 161-178). Londres: Routledge.

Haraway, D. (1995). Saberes localizados: a questão da ciência para o feminismo e o privilégio da perspectiva parcial. Cadernos Pagu, 5, 7-41.

Herzog \& De Meuron (2014). Arena do Morro, Natal. Projeto Design, 410. Recuperado em 22 de janeiro de 2016, de https://arcoweb.com.br/projetodesign/arquitetura/ herzog-meuron-arena-morro-natal

Herzog \& De Meuron (2016). 354.1 Arena do Morro Mãe Luiza, Natal. Basel: Herzog \& De Meuron. Recuperado em 22 de janeiro de 2016, de https://www.herzogdemeuron. com/index/projects/complete-works/351-375/354-1arena-do-morro.html

Knorr-Cetina, K. (2001). Postsocial relations: theorizing society in a postsocial environment. In G. Ritzer, \& B. Smart (Eds.), Handbook of social theory (p. 520-537). Londres: Sage.
Latour, B. (2000). Ciência em Ação. São Paulo: Editora UNESP.

Latour, B. (2008). Como falar do corpo? A dimensão normativa dos estudos sobre a ciência. In J. Nunes, \& R. Roque. (Orgs.), Objetos impuros: experiências em estudos sobre a ciência (p. 39-62). Porto: Edições Afrontamento.

Latour, B., \& Yaneva, A. (2008). 'Give Me a Gun and I will Make All Buildings Move': an ANT's view of architecture. In R. Geiser (Ed.), Explorations in architecture: teaching, design, research, basel (p. 80-89). Basileia: Birkhäuser.

Law, J. (2000). Objects, spaces and others. Recuperado em 01 de outubro de 2014, de http://www.comp.lancs.ac.uk/ sociology/ soc027jl.html

Law, J., \& Mol, A. (2000). Situating technoscience: an inquiry into spatialities. Recuperado em 05 de maio de 2015, de http://www.comp.lancs.ac.uk/sociology/papers/Law-MolSituating-Technoscience.pdf

Mol, A. (2008). Política Ontológica: algumas ideias e várias perguntas. In J. Nunes, \& R. Roque (Orgs.), Objetos impuros: experiências em estudos sobre a ciência (p. 63-77). Porto: Edições Afrontamento.

Montaner, J., \& Muxí, Z. (2014). Arquitetura e política: ensaios para mundos alternativos. Barcelona: Gustavo Gili.

Natal. Prefeitura Municipal (2011). Presidente da Ameropa Suíça tem audiência com a prefeita. Natal: Prefeitura Municipal. Recuperado em 18 de fevereiro de 2016, de http://www.natal.rn.gov.br/noticia/ntc-5662.html

Pessoa, D. (2015). Arquiteto espanhol Santiago Calatrava fala sobre o Museu do Amanhã e o Rio. Veja Rio, 1-6.

Rheingantz, P. A. (2015). Museu do Amanhã. Ou o esqueletocyborg de um crocodilo gigante com duas bocas? Minha Cidade, 16(185.05). Recuperado em 27 de abril de 2017, de http://www.vitruvius.com.br/revistas/read/ minhacidade/16.185/5867</jrn>.

Rheingantz, P., Alcantara, D., \& del Rio, V. (2005). A influência do projecto na qualidade do lugar: percepção da qualidade em áreas residenciais no Rio de Janeiro. Sociedade e Território, 39, 98-115.

Santiago Calatrava Architects \& Engineers (2015). Museu do Amanhã - Rio de Janeiro. Recuperado em 19 de fevereiro de 2016, de http://www.calatrava.com/projects/museudo-amanha-rio-de-janeiro.html

Serres, M. (1999). Luzes: cinco entrevistas com Bruno Latour. São Paulo: Unimarco. 
Szapiro, A. (2009). 0 imperativo da utilidade: a hegemonia da técnica e seus efeitos sobre o humano. In A. Szapiro (Org.), Clínica da pós-modernidade (p. 79-92). Rio de Janeiro: Bapera.

The Ameropa Foundation. Binningen. Recuperado em 18 de fevereiro de 2016, de http://www.ameropa-foundation. com/en/ameropa

Vieira, N., \& Dantas, G. (2014). Herzog \& de Meuron projetam a Arena do Morro, um ginásio cultural e poliesportivo em bairro carente de Natal. Revista AU, 242. Recuperado em 22 de janeiro de 2016, de http://au.pini.com.br/arquiteturaurbanismo/242/herzog-de-meuron-projetam-a-arena-domorro-um-ginasio-311264-1.aspx

Recebido: Mar. 02, 2016

Aprovado: Ago. 12, 2016 


\section{Errata}

No artigo Arena do Morro e Museu do Amanhã: dois lugares em ação, com número de DOI: 10.1590/21753369.009.003.A002, p. 387-400, publicado no periódico urbe. Revista Brasileira de Gestão Urbana, v. 9, n. 3, Curitiba Sept./Dec. 2017 Epub July 24, 2017, na página 387,

Onde se lia:

Fabíola Berlinger Angotti ${ }^{[a]}$

Leia-se:

Fabiola Belinger Angotti ${ }^{[a]}$ 